\title{
Study of Acid Treatment Conditions on the Water and Moisture Absorbency of Coconut Coir
}

\author{
Nilofar Asim, Mohamad Hassan Amin, and Kamaruzzaman Sopian
}

\begin{abstract}
The influence of chemical treatment on the properties of lignocellulosic fibers has been reported in many studies. This work analyzes the effect of acid treatment on the water and moisture absorbency of coconut coir. Multiple acidic treatment conditions have been considered for coconut coir via Design of Experimental (DOE) software to optimize its treatment and ensure maximum water and moisture absorbency. The compositional and structural changes of the treated samples were determined using $\mathrm{X}$-ray diffraction (XRD), scanning electron microscope (SEM), X-Ray photoelectron spectroscopy (XPS), Fourier transform infrared (FT-IR), and Thermogravimetric analysis (TGA). The optimized acidic condition led to a treated coconut coir with only an $8 \%$ increment of water absorption, and a $\sim 13 \%$ decrease of moisture absorption. Based on the results, acidic treatment is unsuitable for increasing coconut coir's water and moisture absorbency.
\end{abstract}

Index Terms-Acid treatment, water absorbency, coconut coir.

\section{INTRODUCTION}

Recent research on utilizing waste materials has opened many investigative paths. The investigation of raw and chemically/physically treated waste materials could efficiently determine the best application for many waste materials. It could also optimize both costs and technical performances towards utilizing waste materials for multiple applications [1]. Taking into account the cost and environmental impact of most desiccant materials, researchers focus on employing agricultural wastes as desiccant materials [2]-[5]. There are plenty of local agricultural wastes [6] that can be recycled for increased economic benefits [7]. Many agricultural wastes containing lingocellulosic exhibited increased absorption properties post physical/chemical treatments. The most common chemical treatment methods include acid and alkali treatments [8], which improves the absorption properties of the samples via increased hydrogen bonding, porosities, and lignin removal (i.e., introducing hydrophobicity) [9]. Coconut coir (CC), which consists of lignin, cellulose, and hemi-cellulose natural polymers [10], obtained from the coconut husk (which is cheap and regarded as an agricultural waste material) was selected for further investigation. In this study, a DOE software has been employed to determine acid

Manuscript received November 9, 2018; revised January 2019.

Nilofar Asim and Kamaruzzaman Sopian are with Solar Energy Research Institute, National University of Malaysia, Malaysia (e-mail: nilofarasim@ukm.edu.my, asimnilofar@gmail.com)

Mohamad Hassan Amin is with Centre for Advanced Materials \& Industrial Chemistry, School of Science, RMIT University, Melbourne, VIC 3001, Australia. treatment conditional factors and evaluate treated samples' water and moisture absorption.

\section{EXPERIMENTAL PROCEDURE}

\section{A. Acid Treated Coconut Coir}

Coconut coir was purchased from a local market and used as-received after being cut into small pieces $(1 \mathrm{~cm})$. Sulfuric acid (analytical reagent) and silica gel were procured from Ajax Finechem Pty Ltd. As per literature for acid treatment, the concentration of the solution ranged between $0.4-8 \mathrm{M}$, for 30-180 min at $25-80{ }^{\circ} \mathrm{C}$, which were all keyed into the Design of Experimental software (DOE) version 7 (Stat-Ease Corporation, USA), response surface mode, and central composite design software. The results of the DOE and samples for comparison purposes (results from DOE to proceed to the next steps) are presented in Table I.

\section{WATER AND MOISTURE ABSORPTION ANALYSIS}

The water absorption property of the samples was examined using ASTM D 570-98 to evaluate its performance. The result is the average of a minimum of 3 samples for each treatment condition (Table I). The samples' moisture absorption was then determined. A saturated salt-water system was prepared as per the standard practice outlined in ASTM E104-02. The moisture source used $\mathrm{NaCl}$ solution to maintain a constant humidity at different times at a fixed temperature of $28 \pm 2{ }^{\circ} \mathrm{C}$ (Humidity $=75 \%-50 \%$ ) [11]. The result is the average of a minimum of 3 samples for each treatment condition(s) (Table I). Many samples completely lost its fibers' shape and strength post acidic treatment, rendering them unsuitable for water and moisture absorbency tests. The results confirmed that there is an $\sim 8 \%$ increment of water absorption in the case of the best acid treated samples (Sample 6) relative to the raw $\mathrm{CC}$, where the moisture absorption decreased by $\sim 13 \%$.

\section{CHARACTERIZATION}

Thermogravimetric analysis (TGA, Perkin Elmer TG7) was used (temperature range of $30-800{ }^{\circ} \mathrm{C}$ under air flow) to determine the thermal stability of the prepared samples. The weight loss of the acid treated CC being less than that of the raw specimen was evident. Reference [12] pointed out that the increased thermal stability is due to the partial removal of lignin, hemicelluloses, and $\alpha$-cellulose from the fiber caused by acid treatment. The TGA plots of the treated samples were compared at similar temperatures and times but different $\mathrm{H}_{2} \mathrm{SO}_{4}$ concentrations (Fig. 1). The results showed that 
increased molarity, from 0.4 to $1 \mathrm{M}$, increased the samples' thermal stability, while increasing the concentration from 1 to
4 M caused the samples' thermal stability to slightly decrease.

TABLE I: THE DIFFERENT $\mathrm{H}_{2} \mathrm{SO}_{4}$ TREATMENT CONDITIONS UTILIZED FOR COCONUT COIR(CC) USING DOE SOFTWARE

\begin{tabular}{|c|c|c|c|c|c|}
\hline Sample & $\begin{array}{c}\text { Concentration } \\
(\mathrm{M})\end{array}$ & $\begin{array}{c}\text { Temperature } \\
\left({ }^{\circ} \mathrm{C}\right)\end{array}$ & $\begin{array}{l}\text { Time } \\
\text { (Min) }\end{array}$ & $\begin{array}{c}\text { Water } \\
\text { Absorption\% }\end{array}$ & $\begin{array}{c}\text { Moisture } \\
\text { Absorption\% }\end{array}$ \\
\hline 1 & 0.4 & 80 & 180 & - & - \\
\hline 2 & 0.4 & 25 & 30 & 116 & 6.3 \\
\hline 3 & 0.4 & 2 & 180 & 143 & 6.2 \\
\hline 4 & 0.4 & 80 & 30 & 165 & 5.6 \\
\hline 5 & 0.4 & 30 & 40 & 136 & 6.9 \\
\hline 6 & 1 & 30 & 40 & 155 & 7.3 \\
\hline 7 & 2.2 & 30 & 40 & 130 & 6.6 \\
\hline 8 & 2.2 & 52 & 105 & - & - \\
\hline 9 & 2.2 & 52 & 231 & - & - \\
\hline 10 & 2.2 & 99 & 105 & - & - \\
\hline 11 & 4 & 25 & 30 & 129 & 6.5 \\
\hline 12 & 4 & 25 & 180 & - & - \\
\hline 13 & 4 & 30 & 40 & 132 & 6.5 \\
\hline 14 & 4 & 80 & 30 & - & - \\
\hline 15 & 4 & 80 & 180 & - & - \\
\hline 16 & 5 & 52 & 105 & - & - \\
\hline $\begin{array}{c}\text { Raw } \\
\text { CC } \\
\text { Silica } \\
\text { gel }\end{array}$ & - & - & - & 144 & 8.4 \\
\hline
\end{tabular}

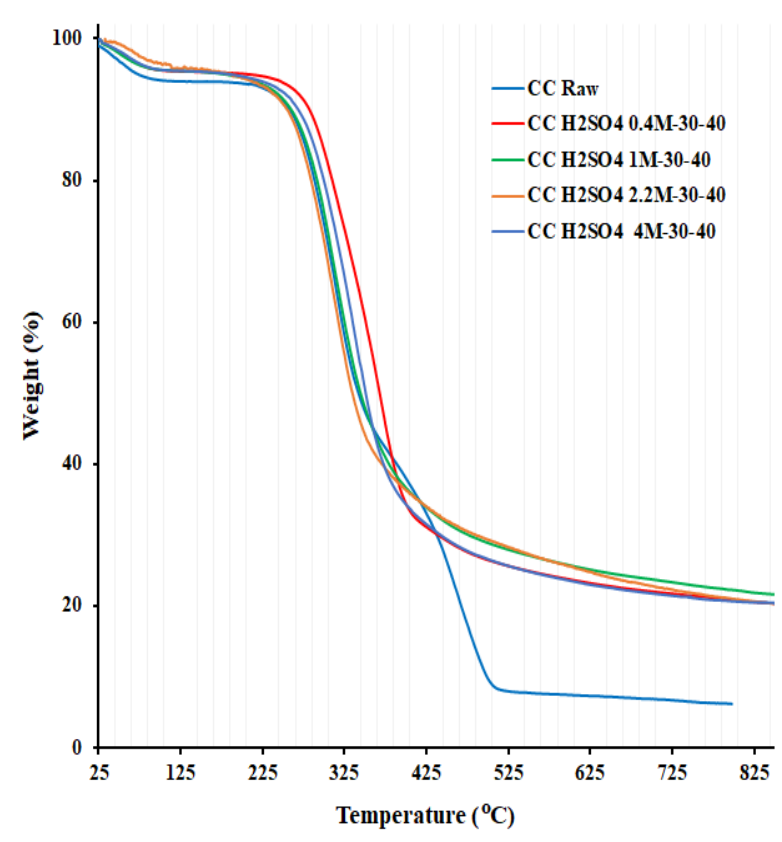

Fig. 1. TGA results for raw and treated samples.

The FT-IR spectroscopic analysis (Perkin Elmer, Frontier) was used to identify the functional groups present in the raw coconut coir and the treated samples (Fig. 2).

The XRD plots of the prepared samples are shown in Fig. 3. The samples reported similar patterns. Coconut coir contains cellulose, hemicellulose, lignin, and crystalline cellulose. Peaks at $\sim 16^{\circ}, 22^{\circ}$, and $35^{\circ}$ are attributed to cellulose [13], [14], which are crystalline due to hydrogen bonding and Van der Waals interactions [15], [16]. Variance in acidic treatment did not influence the crystallinity of cellulose.

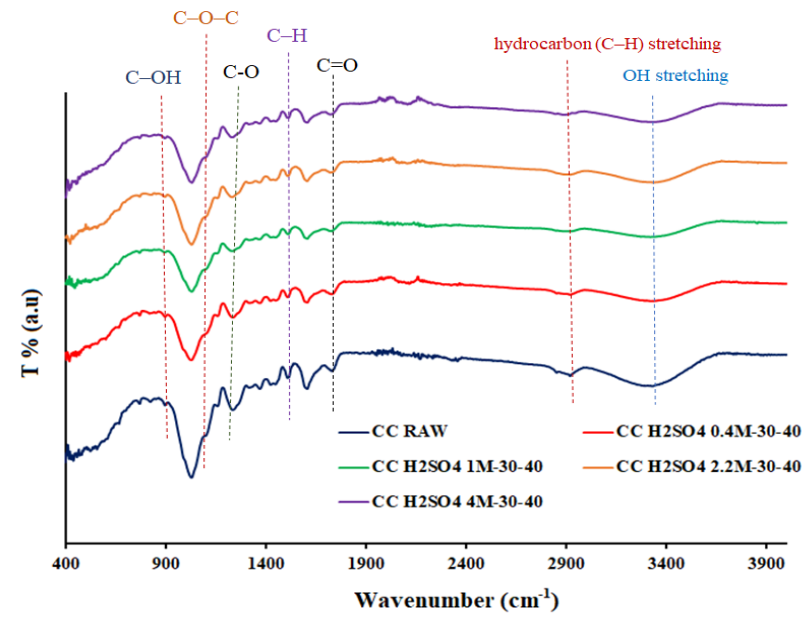

Fig. 2. FTIR spectra of raw $\mathrm{CC}$ and some treated samples.

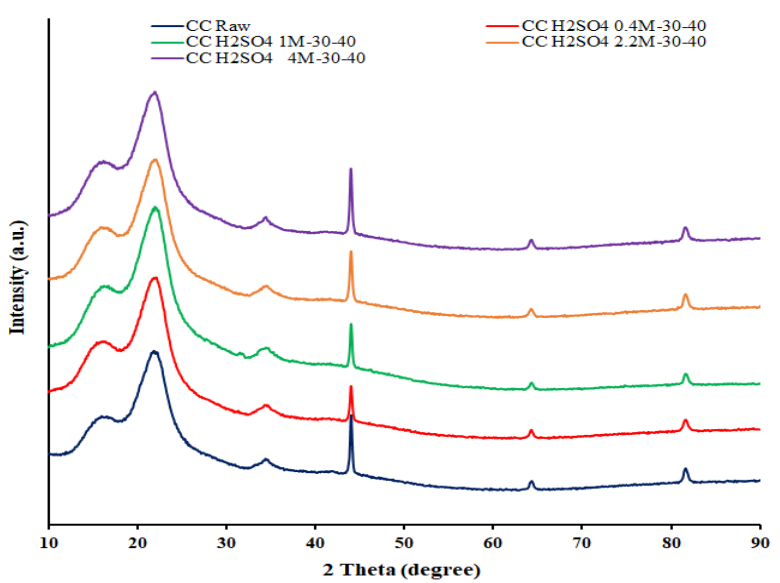

Fig. 3. The XRD patterns for raw and selected acid treated coconut coirs. 
Morphological studies of raw and treated coconut coir were conducted by SEM, using a Philips XL30 (Fig. 4.)
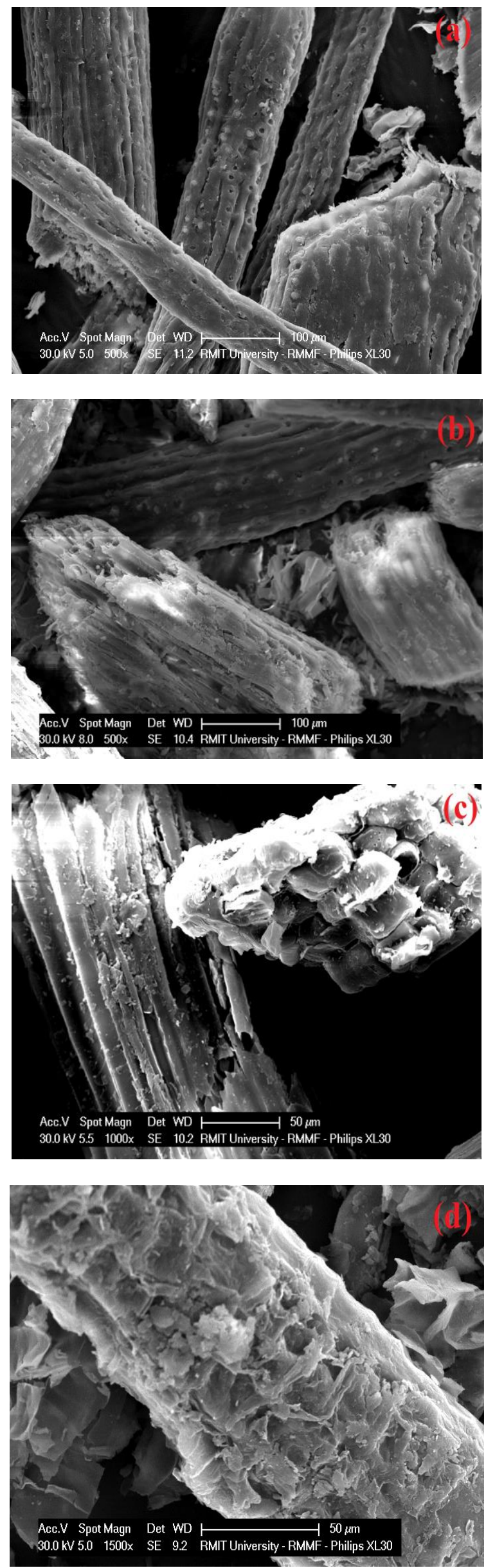

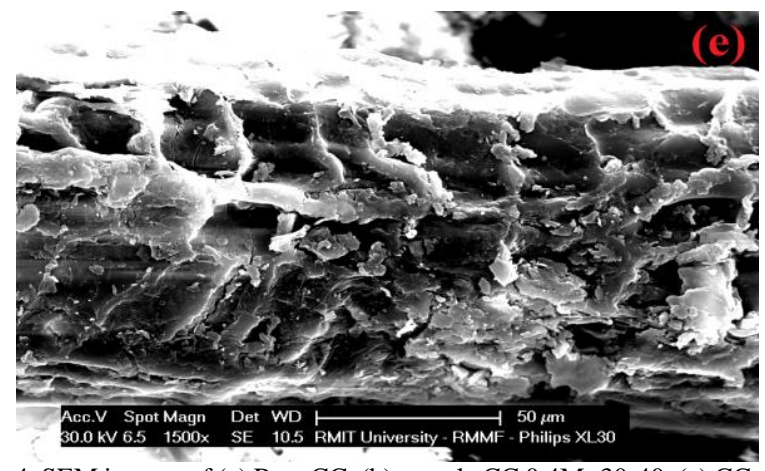

Fig. 4. SEM images of (a) Raw CC, (b) sample CC 0.4M- 30-40, (c) CC 1M30-40, (d) CC 2.2M- 30-40 and (e) CC 4M- 30-40, respectively.
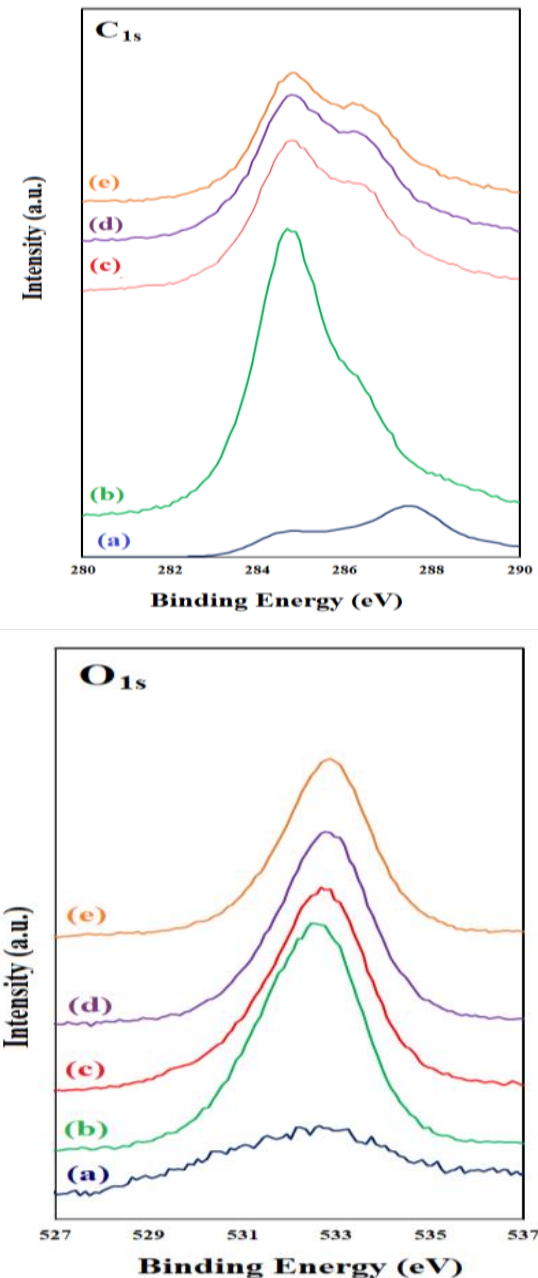

Fig. 5. XPS high-resolution C1s and O1s spectra of (a) CC Raw, (b) CC H2SO4 0.4M- 30-40, (c) CC H2SO4 1M- 30-40, (d) CC H2SO4 2.2M- 30-40, (e) CC H2SO4 4M- 30-40, respectively.

Scanning electron microscopy (SEM) images of the fibers' surfaces exhibited a layer of extractives being removed post acidic treatment. The acid-treated samples showed porous structural features relative to that of raw $\mathrm{CC}$, with some of the pores ruptured and others breaking apart.

$\mathrm{X}$-ray photoelectron spectroscopy was used to investigate changes to the chemical structure of the outermost $3-10 \mathrm{~nm}$ of the treated surfaces (Fig. 5.). The results showed that $\mathrm{C}$ and $\mathrm{O}$ are the predominant species in all of the tested samples. The presence of $\mathrm{N}$ and $\mathrm{Si}$ on the surface of some of the samples was also detected from their characteristic emission peaks. The N1s line, with a binding energy value of $\sim 400 \mathrm{eV}$, corresponds to the $-\mathrm{NH} 2$ group in amino acids/proteins found in small amounts on the surface of some lignocellulose 
materials, while $\mathrm{Si}$ is an impurity. The standard binding energy of $\mathrm{C} 1 \mathrm{~s}$ is $\sim 285 \mathrm{eV}$, while the binding energies of $\mathrm{C} 1(\mathrm{C}-\mathrm{C}, \mathrm{C}=\mathrm{C}, \mathrm{C}-\mathrm{H}), \mathrm{C} 2(-\mathrm{O}, \mathrm{C}-\mathrm{O}-\mathrm{C}), \mathrm{C} 3(\mathrm{C}=\mathrm{O}, \mathrm{O}-\mathrm{C}-\mathrm{O})$ and $\mathrm{C} 4(\mathrm{O}-\mathrm{C}=\mathrm{O}, \mathrm{C}(=\mathrm{O}) \mathrm{OH})$ are located at $285 \mathrm{eV}, 286.7 \mathrm{eV}$, $288.3 \mathrm{eV}$, and $289.5 \mathrm{eV}$, respectively. Based on many reported results pertaining to the lingocellulosic materials [17], the amount of $\mathrm{C} 1$ in XPS represents the quantity of non-carbohydrate bindings in the materials, only present in lignin. On the other hand, $\mathrm{C} 2, \mathrm{C} 3$, and $\mathrm{C} 4$ are mainly present in carbohydrates. The result shows the shift from higher binding energies to lower binding energies $(\mathrm{eV})$ in $\mathrm{C} 1 \mathrm{~s}$ with increasing concentrations of $\mathrm{H}_{2} \mathrm{SO}_{4}$, which means that the decreased carbohydrate in the treated samples could be attributed to increased removal or degradation of carbohydrate compared to the lignin in treated CC. It could also be used to explain the decreased water and moisture absorption due to increased concentration of $\mathrm{H}_{2} \mathrm{SO}_{4}$.

Typically, the standard electron binding energy of $\mathrm{O} 1 \mathrm{~s}$ is $\sim 532 \mathrm{eV}$, exhibiting two valence states such as $\mathrm{O} 1(\mathrm{C}=\mathrm{O})$ at $\sim 531.4-532.3 \mathrm{eV}$ and $\mathrm{O} 2(\mathrm{C}-\mathrm{O})$ at $\sim 533.0-534.0 \mathrm{eV}$. According to literature, $\mathrm{O} 1$ with low binding energy comes from lignin, while $\mathrm{O} 2$ with the high binding energy comes mainly from carbohydrates in lingocellulosic materials [18]-[20].

\section{CONCLUSIONS}

Although acid treatment of coconut coir changes its morphology and the composition of the fibers based on the treatment conditions, there are no significant improvements to its water and moisture absorbency properties. The results showed that acidic treatment cannot be regarded as a suitable treatment for water and moisture absorbency. The samples seem to show reduced carbohydrate at levels higher than that of lignin in coconut coir fibers and decreased active hydroxyl groups on their surfaces.

\section{ACKNOWLEDGMENT}

The authors gratefully acknowledge the financial support of the Endeavour Scholarships and Fellowships program (Australian Government). In addition, the authors acknowledge the facilities, and the scientific and technical assistance, of the Australian Microscopy \& Microanalysis Research Facility at RMIT University.

\section{REFERENCES}

[1] N. Asim et al., "Perspective of agriculture wastes usage as a resource," Advanced Materials Research, vol. 550-553, pp. 2246-2254, 2012.

[2] Z. Emdadi et al., "Feasibility study of using rice husk and its treated forms with Alkali Solution as a desiccant material," WSEAS Transactions on Environment and Development, vol. 10, pp. 306-311, 2014.

[3] J. Khedari, S. Charoenvai, and J. Hirunlabh, "New insulating particleboards from durian peel and coconut coir," Building and Environment, vol. 38, no. 3, pp. 435-441, 2003.

[4] J. B. Williams, "Evaluation of kenaf core as a desiccant," Department of Animal and Dairy Science Box 9815 Mississippi State, 1999, MS 39762.

[5] N. Asim et al., "Agricultural solid wastes for green desiccant applications: An overview of research achievements, opportunities and perspectives," Journal of Cleaner Production, vol. 91(Supplement C), pp. 26-35, 2015.

[6] Z. Emdadi et al., "Chemically treated rice husk blends as green desiccant materials for industrial application," Chemical Engineering \& Technology, vol. 40, no. 9, pp. 1619-1629, 2017.
[7] T. Ziegler, I. G. Richter, and R. Pecenka, "Desiccant grain applied to the storage of solar drying potential," Drying Technology, vol. 17, no. 7-8, pp. 7-8, 1999.

[8] L.Y. A. M. P. Mwaikambo, "Chemical modification of hemp, sisal, jute, and kapok fibers by alkalization," Journal of Applied Polymer Science, vol. 84, no. 12, pp. 2222-2234, 2002.

[9] Z. Emdadi et al., Chemically Treated Rice Husk Blends as Green Desiccant Materials for Industrial Application 2017, Universiti Kebangsaan Malaysia.

[10] P. J. M. C. Suhas and M. M. L. R. C. Lignin, "From natural adsorbent to activated carbon: A review," Bioresource Technology, vol. 98, no. 12, pp. 2301-2312, 2007.

[11] 104, A. E., Standard Practice for Maintaining Constant Relative Humidity by Means of Aqueous Solutions. American Society for Testing of Materials, Philadelphia, USA, 2002.

[12] M. M. Kabir et al., "Effects of chemical treatments on hemp fibre structure," Applied Surface Science, vol. 276, pp. 13-23, 2013.

[13] D. Klemm et al., "Cellulose: Fascinating biopolymer and sustainable raw material," Angewandte Chemie International Edition, vol. 44, no. 22, pp. 3358-3393, 2005

[14] S. Park et al., "Cellulose crystallinity index: Measurement techniques and their impact on interpreting cellulase performance," Biotechnology for Biofuels, vol. 3, p. 10, 2010.

[15] N. Johar, I. Ahmad, and A. Dufresne, "Extraction, preparation and characterization of cellulose fibres and nanocrystals from rice husk," Industrial Crops and Products, vol. 37, no. 1, pp. 93-99, 2012.

[16] Y. H. P. Zhang and L. R. Lynd, "Toward an aggregated understanding of enzymatic hydrolysis of cellulose: Noncomplexed cellulase systems," Biotechnology and Bioengineering, vol. 88, no. 7, pp. 797-824, 2004.

[17] C. Huang, Q. Yang, and S. Wang, "XPS characterization of fiber surface of chemithermomechanical pulp fibers modified by white-rot fungi," Asian Journal of Chemistry, vol. 24, no. 12, pp. 5476-5480, 2012.

[18] C. M. Popescu, C.-M. Tibirna, and C. Vasile, "XPS characterization of naturally aged wood," Applied Surface Science, vol. 256, no. 5, pp. 1355-1360, 2009.

[19] X. Hua et al., "Surface analysis of explosion pulps by ESCA," Wood Science and Technology, vol. 28, no. 1, pp. 1-8, 1993.

[20] A. O. Barry, Z. Koran, and S. Kaliaguine, "Surface analysis by ESCA of sulfite post-treated CTMP," Journal of Applied Polymer Science, vol. 39, no. 1, pp. 31-42, 1990.

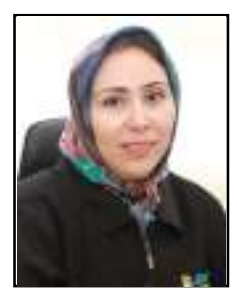

Nilofar Asim was born in Tabriz, Iran in 1970. She obtained her BSc in in applied chemistry, MSc in inorganic chemistry from Tehran University (Iran) and $\mathrm{PhD}$ in materials science from National university of Malaysia.

She is presently working at Solar Energy Research Institute, a center of excellence for the research and development in solar energy technology, Universiti Kebangsaan Malaysia. She has been involved in the field of materials science for more than 17 years. Dr. Nilofar Asim's main contributions are in synthesis of nanomaterials (metal oxide and composite), photocatalysts, inorganic polymers and agriculture waste materials modification for new applications. She has published more than 70 research papers in journals and conferences.

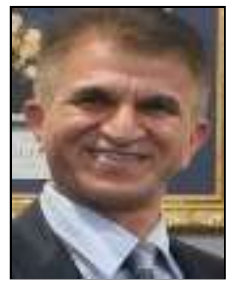

Mohamad Hassan Amin is a retired a professor in material engineering (ceramics). Currently, he is employed as a research scientist with the Centre for Advanced Materials \& Industrial Chemistry, within the School of Sciences at RMIT University, Australia.

Dr Amin possesses 15+ years of industrial and academic experience and expertise in the synthesis and characterisation of new materials, heterogeneous catalysis, nanomaterials, refractory ceramics, and $\mathrm{CO} 2$ reforming of methane for the production of syngas, methanol and liquid fuels. He has published $90+$ refereed papers in leading material science and chemistry journals, and three chemistry textbooks, and also holds 18 patents. Previously he was a visiting fellow at the University of New South Wales, Australia (2005-2006). He worked as a/professor in Azad University of Yazd and Materials and Energy Research Centre (MERC) in Tehran (2006- 2009), which has included performing the role of head of the Ceramics Department with MERC, head of Chemistry Department and director of Research Department with Azad University Iran. Dr. Amin is a member of Royal Australian Chemical Institute (RACI). 


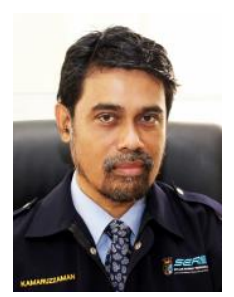

Kamaruzzaman Bin Sopian obtained his BSc in mechanical engineering from the University of WisconsinMadison in 1985, MSc in energy resources from the University of Pittsburgh in 1989 and $\mathrm{PhD}$ in mechanical engineering from the Dorgan Solar Laboratory, University of Miami in 1997.

$\mathrm{He}$ is presently a professor in renewable energy at the Department of Mechanical and Material Engineering, Universiti Kebangsaan Malaysia. Currently, he is the director of the Solar Energy Research Institute, a center of excellence for the research and development in solar energy technology. He has been involved in the field of solar energy for more than twenty years. His main contributions are in solar radiation modeling, alternative material for solar absorber, solar water heating system with integrated storage system, solar desalination, solar cooling, daylighting using solar light pipes, solar assisted drying systems, gridconnected photovoltaic system, thin film silicon solar cells, combined photovoltaic thermal or hybrid collector and solar hydrogen production system. He has published over 400 research papers in journals and conferences. 